\title{
Rheumatoid Vasculitis Following Change to Naturopathic Remedies
}

\author{
Graeme Prosperi-Porta, MD MASc, Ben John Wilson, MD
}

Department of Medicine, Cumming School of Medicine, University of Calgary, Calgary, AB, Canada Adresse pour correspondance: Graeme Prosperi-Porta: Email: Graeme.prosperiporta@ucalgary.ca Received: 27 March 2020; Accepted: 27 April 2020; Published: 26 March 2021.

DOI: http://dx.doi.org/10.22374/cjgim.v16i1.439

A 66-year-old female with seropositive rheumatoid arthritis (RA) complicated by cutaneous and pulmonary nodules presented to hospital with progressive painful black discoloration on the plantar aspect of her right great toe (Figure 1). Five months prior, she had discontinued sulfasalazine, methotrexate, hydroxychloroquine, and infliximab due to medication-attributed side effects in favor of naturopathy. Podiatric surgery performed a great toe amputation through the first metatarsal head for a diagnosis of "gangrene" without further investigations.

Two weeks later, the patient returned with bilateral foot pain and new multifocal, painless raised fluid-filled black lesions on her toes and distal forefeet, and a black ulceration medioproximal to the amputation site (Figure $2 \mathrm{~A}-\mathrm{B}$ ). She also complained of a one-month history of bilateral foot drop. She had no Reynaud's phenomenon, was afebrile, and had a leukocyte count of $7.7 \times$

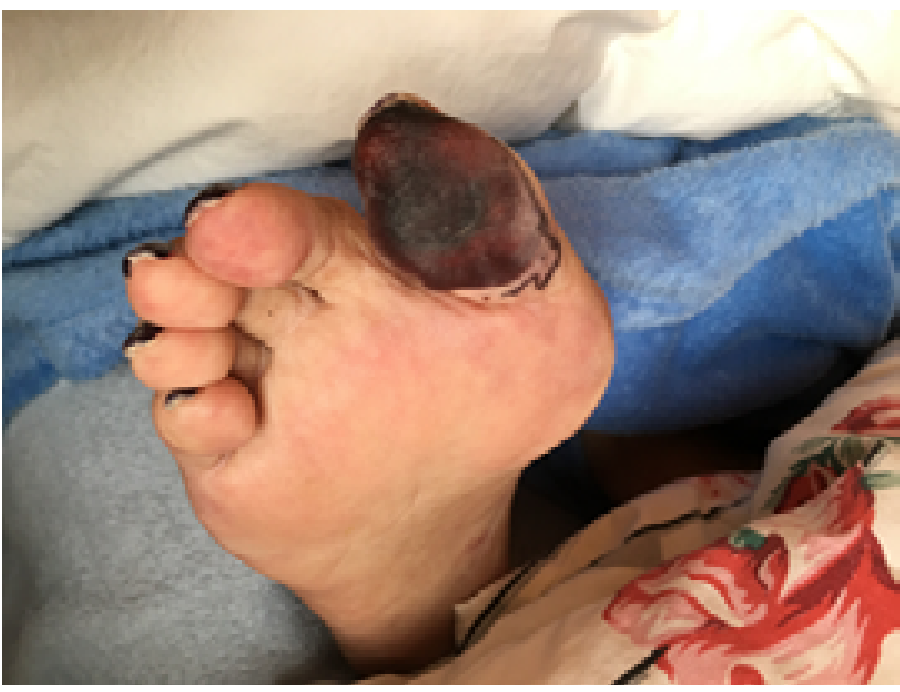

Figure 1. Right great toe on first hospital visit diagnosed as "gangrene."
$10 \mathrm{E} 9 / \mathrm{L}(4.0-11.0 \times 10 \mathrm{E} 9 / \mathrm{L})$, with negative blood and urine cultures. Her rheumatoid factor was $2020 \mathrm{kU} / \mathrm{L}(0-20 \mathrm{kU} / \mathrm{L})$ and anti-cyclic citrullinated peptide was $178.5 \mathrm{U} / \mathrm{mL}(0-4.9$ $\mathrm{U} / \mathrm{mL}$ ). Her anti-nuclear antibody, C3, C4 cryoglobulin, and ANCA levels were unremarkable. Human immunodeficiency virus, hepatitis $B$, and hepatitis $C$ were negative. Transesophageal echocardiography showed no valvular vegetation and computed tomography angiography showed mild diffuse vascular disease without proximal lesions or polyarteritis nodosa. Electromyography showed a severe length-dependent sensorimotor axonal polyneuropathy consistent with mononeuritis multiplex. She was diagnosed with rheumatoid vasculitis.

Despite three intravenous doses of methylprednisolone $1 \mathrm{~g}$, two doses of intravenous rituximab $1 \mathrm{~g}$, and twice-daily oral sulfasalazine $1 \mathrm{~g}$, she underwent bilateral transmetatarsal amputations for disease progression. No histologic examination was performed as the diagnosis was confirmed clinically and biochemically.

Rheumatoid vasculitis, a severe extra-articular manifestation of RA, is predominantly seen in longstanding seropositive RA with other extra-articular manifestations. ${ }^{1}$ High serum rheumatoid factor and anti-cyclic citrullinated peptide are associated with RA vasculitis. ${ }^{2}$ While its incidence has decreased in the modern therapeutic era from 9.1 to 3.9 cases per million in 1998-2000 to 2000-2010, respectively, rheumatoid vasculitis has a 5-year mortality between 30 and $60 \%$ from organ involvement and treatment complications. ${ }^{1-3}$

If RA vasculitis was considered during the patient's initial presentation for "gangrene," early immunosuppression may have prevented disease progression requiring bilateral transmetatarsal amputations. This case reminds clinicians to consider vasculitis in any RA patient with new skin findings and to strongly dissuade patients from pursuing only naturopathic remedies, 


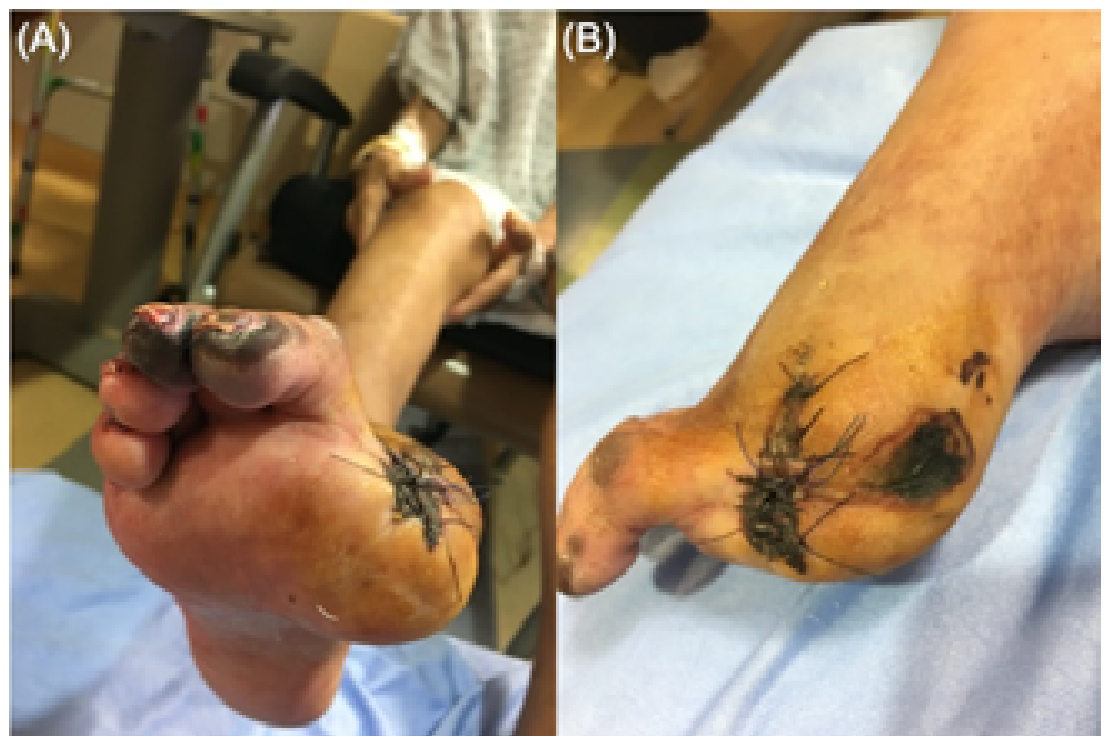

Figure 2. Right foot following great toe amputation showing (A) distal foot and (B) postsurgical site.

as disease-modifying medical therapies have been shown to prevent RA complications such as vasculitis. ${ }^{4}$

\section{Competing Interests}

The authors declare that they have no financial or nonfinancial competing interests related to this case report.

\section{Funding}

There is no funding associated with this case report.

\section{Author's Contributions}

GPP and BW were involved directly in diagnosis and patient care. GPP and BW prepared the manuscript. All authors read and approved the final manuscript.

\section{References}

1. Bartels CM, Bridges AJ. Rheumatoid vasculitis: Vanishing menace or target for new treatments? Curr Rheumatol Rep. 2010;12(6):414-19. http://dx.doi. org/10.1007/s11926-010-0130-1

2. Turesson C, Jacobsson LT, Sturfelt G, Matteson EL, Mathsson L, Ronnelid J. Rheumatoid factor and antibodies to cyclic citrullinated peptides are associated with severe extra-articular manifestations in rheumatoid arthritis. Ann Rheum Dis. 2007;66(1):59-64. http://dx.doi.org/10.1136/ ard.2006.054445

3. Ntatsaki E, Mooney J, Scott DG, Watts RA. Systemic rheumatoid vasculitis in the era of modern immunosuppressive therapy. Rheumatology (Oxford). 2014;53(1):145-52. http://dx.doi.org/10.1093/rheumatology/ket326

4. Singh JA, Saag KG, Bridges SL, Jr., Akl EA, Bannuru RR, Sullivan MC, et al. 2015 American College of Rheumatology guideline for the treatment of rheumatoid arthritis. Arthritis Care Res (Hoboken). 2016;68(1):1-25. http:// dx.doi.org/10.1002/acr.22783 